\title{
Recurrent Anaplastic Oligodendroglioma
}

National Cancer Institute

\section{Source}

National Cancer Institute. Recurrent Anaplastic Oligodendroglioma. NCI Thesaurus. Code C142862.

The reemergence of anaplastic olig odendrog lioma after a period of remission. 